\title{
Pedagogical Senses of Digital Learning ion the Context of the Covid-19 Pandemic: Case Studies of Several Eastern European Countries
}

\author{
Julia Koinova-Zoellner*a, Aydar Kalimullin ${ }^{b}$, \\ Boncho Gospodinov', Miroslav Procházka ${ }^{\mathrm{d}}$ \\ and Liudmila Vasilievae \\ aTU Dresden \\ Dresden, Germany \\ ${ }^{b}$ Kazan Federal University \\ Kazan, Russian Federation \\ 'Sofia University «St. Kliment Ohridski» \\ Sofia, Bulgaria \\ ${ }^{d}$ University of South Bohemia \\ Ceske Budejovice, Czech Republic \\ eShevchenko Transnistria State University \\ Tiraspol, Moldova
}

Received 25.07.2021, received in revised form 04.08.2021, accepted 10.08.2021

\begin{abstract}
In the context of the Covid-19 pandemic, teacher education at universities has faced great problems concerning the teaching-learning practice. Educational processes have become possible only with the help of digital technologies. The development of digital technologies and the new level of accessibility to educational resources have opened up new ways for teaching and learning and the creation of new didactic scenarios. The reopening of educational institutions after the Covid-19 is followed by many tasks that challenge the main actors in the teaching-learning process in a new way. The authors reflect on whether it makes sense for teachers and future teachers to continue learning how to work with digital technologies and create new learning formats for their students. In order to develop teacher education at universities and serious attention to digital didactics, not only the challenges but also the pedagogical senses of the Covid-19 pandemic need to be identified. The unconscious and «detached» perception of current digital transformations in educational policy, higher teacher education and school education hinders the development of teacher education at the university and decreases the role of the teacher in society. A comparative analysis of cases of teacher education from five Eastern European universities is used to address these goals. The analysis aims to examine the hypotheses stated with inductive reasoning.
\end{abstract}

\footnotetext{
(C) Siberian Federal University. All rights reserved

* Corresponding author E-mail address: julia.koinova-zoellner@tu-dresden.de, kalimullin@yandex.ru, bvgospodinov@yahoo. com, mproch@pf.jcu.cz, fakultetfpp@mail.ru

ORCID: 0000-0002-3414-2491 (Koinova-Zoellner); 0000-0001-7788-7728 (Kalimullin); 0000-0001-7108-6102 (Gospodinov); 0000-0003-2797-5089 (Procházka); 0000-0003-4978-1250 (Vasilieva)
} 
Keywords: pedagogical senses of the Covid-19 pandemic, comparative analysis, digital learning, digital competencies, digital teaching and learning challenges.

The research was carried out at the expense of the Program of Strategic Academic Leadership of Kazan (Volga Region) Federal University.

Research area: pedagogy.

Citation: Koinova-Zoellner, Ju., Kalimullin, A. Gospodinov, B., Procházka, M., Vasilieva, L. (2021). Pedagogical senses of digital learning ion the context of the Covid-19 pandemic: case studies of several eastern european countries. J. Sib. Fed. Univ. Humanit. soc. sci., 14(9), 1355-1364. DOI: 10.17516/1997$1370-0825$

\title{
Педагогические смыслы цифрового обучения в условиях пандемии Covid-19: \\ анализ кейсов отдельных восточно-европейских стран
}

\author{
Ю. Койнова-Цёльнер ${ }^{\text {, А. Калимуллин }}{ }^{6}$, Б. Господинов \\ М. Прохазкаг, Л. Васильеван \\ ${ }^{a}$ Технический университет Дрездена \\ Германия, Дрезден \\ ${ }^{6}$ Казанский (Приволжский) федеральный университет \\ Российская Федерачия, Казань \\ ${ }^{6}$ Софийский университет им. Св. Климента Орхидского \\ Болгария, София \\ 'Южно-чешский университет \\ Чехия, Ческе Будеевиче \\ 'Приднестровский государственный университет \\ Молдавия, Тирасполь
}

Аннотация. В условиях пандемии Covid-19 университетское педагогическое
образование столкнулось с большими проблемами реализации процесса обучения.
Образовательные процессы стали возможны лишь с помощью цифровых
технологий. Вынужденное развитие цифровых технологий и новый уровень
доступности к образовательным ресурсам открыли новые возможности для
обучения и создания новых дидактических сценариев. Постепенное возобновление
работы учебных заведений после начала пандемии Соvid-19 сопровождается
многочисленными задачами, которые бросают новый вызов основным участникам
учебного процесса. Имеет ли смысл преподавателям и будущим учителям учиться
дальше работать с цифровыми технологиями и создавать новые форматы обучения
для своих будущих учеников? Для развития университетского педагогического
образования и формирования осознанного отношения к цифровой дидактике нужно
определить не только вызовы, но и педагогические смыслы пандемии Соvіd-19
как эпохального события в образовании. Неосознанное и «отрывное» восприятие
актуальных цифровых трансформаций в образовательной политике высшего
педагогического и школьного образования тормозит развитие педагогического
университетского образования и снижает роль учителя в обществе. Для решения 
поставленных целей используется компаративный анализ кейсов педагогического образования пяти восточно-европейских университетов. Анализ нацелен на проверку сформулированных гипотез с использованием индуктивного метода исследования.

Ключевые слова: педагогические смыслы пандемии, компаративный анализ, обучение в цифровом формате, цифровые компетентности, вызовы обучения в цифровом формате.

Исследование выполнено за счет средств Программы стратегического академического лидерства Казанского (Приволжского) федерального университета.

Научная специальность: 13.00 .00 - педагогические науки.

\section{Введение}

Во всех университетах мира закончился третий семестр обучения в условиях пандемии Covid-19. Учитывая масштабы пандемии и время введения первого полного локдауна, можно поразиться скорости и масштабу введения цифрового преподавания и обучения, который на начальном этапе воспринимался как «запасной выход» из создавшейся чрезвычайной ситуации, получивший название «emergency remote teaching». Никогда еще меры по цифровизации образования не были так важны, а введение цифрового образования не проводилось так быстро. В течение нескольких недель были внедрены сценарии цифрового обучения, которые до пандемии рассматривались как возможность в преподавании, но не как необходимость. Следовательно, пандемия Covid-19 бросила вызов всей системе педагогического образования, поскольку реализация образования на всех ступенях обучения была возможна только в цифровом формате. Вопросы: «что означает обучение в цифровом формате», «эффективность обучения в цифровом формате», «факторы, способствующие реализации образования с использованием цифровых инструментов» побудили педагогическое сообщество переосмыслить категории времени и места обучения, оценить на практике уровень цифровых компетенций преподавателей. Опыт преподавания и обучения в цифровом формате в течение трех семестров позволяет сделать промежуточную реф- лексию с точки зрения использования цифровых технологий преподавателями педагогического образования. Как показывает первичный анализ, в университетах, где созданы возможности пользоваться приложениями и доступны лицензии на программное обеспечение, преподавание было реализовано в режиме онлайн с учетом эффективности подготовки будущих учителей. В процессе цифровых занятий в большем объеме были реализованы задачи студенческого инициирования и поддержка автономных процессов обучения. Развитие самостоятельности в обучении студентов уже сегодня имеет большое значение в высшем и школьном образовании и особенно в университетском педагогическом образовании. При этом неосознанное и «отрывное» восприятие актуальных цифровых трансформаций в образовательной политике высшего педагогического и школьного образования тормозят развитие педагогического университетского образования и снижают роль учителя в обществе. В этой связи представляется важным определение новых педагогических смыслов цифрового образования в создавшемся конфликтогенном поле между новыми вызовами и традиционными формами обучения и преподавания. Необходима рефлексия преподавания и обучения, поскольку университетам предстоит планирование образовательной программы в контексте «неизвестности», исходя из опыта обучения в ситуации Covid-19 и учета критерия эффективности, опыт обучения в услови- 
ях пандемии поможет развитию образовательных технологий с использованием цифровых сценариев, компетенций у преподавателей и их самооценке цифровых компетенций, а также определению роли и доли цифрового обучения в педагогическом образовании будущего.

Цель данного исследования - определение педагогических смыслов пандемии и цифровой дидактики, анализ вызовов преподавания в условиях пандемии Covid-19. С помощью индуктивного метода исследования необходимо проверить обоснованность следующих гипотез: (1) осознание педагогических смыслов преподавания в условиях пандемии поможет преодолеть принятие цифрового образования как временного, неприятного и конфликтогенного состояния в педагогическом образовании; (2) цифровая дидактика не заменяет образовательные технологии, являясь эффективным обогащением очного обучения. При этом значимость педагогических профессий повышается.

Для определения уровня развития цифровой компетентности преподавателей в университетском педагогическом образовании была использована модель цифровой компетентности, разработанной Европейской комиссией (DigComEdu, 2018).

Актуальность исследования заключается том, что в отличие от проведенных международных и национальных анализов образования в условиях пандемии Covid-19 (Arzhanova et al., 2020; Galazhinskii, 2020; Gafurov et al., 2020; Ivanova, 2021; Duschinská \& High, 2020; Menter, 2021; Mizova et al., 2021; Vančura \& Rokos, 2020) данное исследование сфокусировано на анализе университетского педагогического образования глазами преподавателей, активных участников процесса обучения «до» и «в условиях» пандемии Covid-19. Особую значимость исследованию придает выборка международных кейсов на примере избранных восточно-европейских университетов, а также задача определения не столько вызовов педагогического образования в условиях пандемии, сколько новых педагогических смыслов.

\section{Материалы и методы исследования}

В компаративном исследовании использованы теоретические методы анализа и синтеза, которые позволили выделить ключевые категории преподавания в условиях пандемии Covid-19 на примерах кейсов Технического университета Дрездена (Германия), Казанского федерального университета (Россия), Приднестровского государственного университета им. Т.Г. Шевченко (Приднестровье), Южночешского университета (Чехия), Софийского университета им. Св. Климента Охридского (Болгария). Участники исследовательской группы выбирались при соблюдении следующих принципов: владение русским как языком общения (уровень С); опыт преподавания педагогических дисциплин на педагогическом факультете до и во время пандемии; прямая причастность к педагогическому образованию пролонгированного характера. Использованные эмпирические методы (полуструктурированные анкеты, анализ университетских сайтов и групповая дискуссия) способствовали сбору качественных данных и их максимальной адаптации в контексте поставленных вопросов. Методологическими основаниями исследования являются дидактика взаимозависимости целей, содержания и способов обучения Хайманн (Heimann, 1976) и теория личностных смыслов Леонтьева (Leont'ev, 1999). Как научное понятие «смысл» используется в герменевтике, изучающей толкование и понимание текстов, эпохальных явлений. Обучение в условиях пандемии Covid-19 знаменует собой эпохальный разрез в истории педагогического образования на «до» и «после», который изменил формы и методы обучения. Методом герменевтической рефлексии исследовательская группа провела анализ учебного процесса в университетском педагогическом образовании в условиях пандемии Covid-19, чтобы сознательно регулировать развитие педагогического образования в процессе выхода из пандемии Covid-19. Для компаративного анализа интернациональных кейсов научная группа выделила следующие общие конструкты: (1) реализация цифрового обу- 
чения в педагогического образования в условиях пандемии Covid-19; (2) определение общего уровня развития цифровых компетенций преподавателей педагогического факультета; (3) определение вызовов развития педагогического образования в условиях пандемии Covid-19; (4) осознание новых педагогических смыслов пандемии для дальнейшего развития педагогического образования.

Исследование проводилось в три этапа: (1) индивидуальный: каждый участник готовил письменный материал в виде кейса на уровне своего университета в контексте педагогического образования на основе своего личностного опыта, полуструктурированных анкет и изучения сайтов и практик цифровых сценариев; (2) кооперативный: проводили групповую дискуссию. Участники предоставили свой материал устно, он обсуждался 25 и 28 мая 2021 г. на двух семинарах экспертов в виде групповых обсуждений в формате видеоконференции. В ходе группового обсуждения были определены качественные категории анализа, обоснованные спецификой педагогического образования и выбора кейсов. Дискуссия имела саморегулирующий характер, была инициирована профессором Казанского федерального университета А.М. Калимуллиным и, в целом, осуществлялась участниками самостоятельно в ходе дискуссии и обсуждении докладов. Заключительный этап (3): индивидуально-кооперативный: письменные материалы были подвергнуты индивидуальной обработке для написания совместного текста.

В целях определения уровня развития цифровой компетенции преподавателей была выбрана шкала из трех категорий (DigComEdu, 2018), которая делится на шесть уровней (табл. 1).

\section{Результаты}

1. На данный момент времени в отдельных восточно-европейских университетах лекционные залы и семинарские аудитории все еще частично пустуют, но процесс педагогического образования реализован в новом качественном формате: лекции транслируются онлайн, видеосеминары, практические занятия проводятся и экзамены сдаются из «home-office» или «hybrid». Пандемия Covid-19 поменяла

Таблица 1. Уровни развития цифровой компетентности

Table 1. Levels of development of digital competence

\begin{tabular}{|c|c|c|}
\hline Обозначение & Уровень & Краткое описание \\
\hline $\begin{array}{l}\text { Начальный } \\
\text { ознакомительный }\end{array}$ & A1 & $\begin{array}{l}\text { Отсутствие или незначительный опыт работы с цифровыми } \\
\text { платформами в социальных сетях и профессиональной деятельности }\end{array}$ \\
\hline Практический & A2 & $\begin{array}{l}\text { Пунктуальное использование цифровой техники в профессиональной } \\
\text { деятельности и в социальных сетях }\end{array}$ \\
\hline Инсайдерский & B1 & $\begin{array}{l}\text { Использование цифровой техники в различных контекстах, освоение } \\
\text { стратегий пользования цифровой техникой в социальных сетях } \\
\text { и различных ситуациях }\end{array}$ \\
\hline Экспериментальный & B2 & $\begin{array}{l}\text { Владение многообразием цифровых техник, постоянное освоение } \\
\text { новых технических технологий, возможность оценки эффективности } \\
\text { использования цифровых стратегий в социальных сетях и различных } \\
\text { ситуациях }\end{array}$ \\
\hline Лидерский & $\mathrm{C} 1$ & $\begin{array}{l}\text { Владение широким репертуаром стратегий с использованием } \\
\text { цифровой техники в социальных сетях и профессионально, } \\
\text { способность передавать знания, в различных ситуациях может } \\
\text { выступать ментором для других }\end{array}$ \\
\hline $\begin{array}{l}\text { Экспертно- } \\
\text { новаторский }\end{array}$ & $\mathrm{C} 2$ & $\begin{array}{l}\text { Развитие новых цифровых технологий в различных контекстах, } \\
\text { дидактиках, пример для других }\end{array}$ \\
\hline
\end{tabular}


жизнь преподавателей и студентов и заставила освоить новые образовательные технологии и пространства. Для этого университеты участников научной группы используют следующие цифровые ресурсы (табл. 2).

2. Анализ ответов на вопрос «Ваши ориентиры в преподавании в условиях Covid-19 пандемии» показал, что общим и характерным для всех участников опроса является ориентация на студентов как основной принцип в организации преподавания. В таком случае можно предположить, что пандемия способствовала качественным изменениям в культуре преподавания, которые выражаются в трансформации фокуса преподавания и отказе от репродуктивной активности преподавателя в пользу увеличения студенческой активности, «Shift from teaching to learning» (Becker \& Stang, 2020; Pasternak et al., 2018). Преподавательская активность в условиях пандемии Covid-19 сфокусирована на подготовку цифровой платформы общения, владения инструментами программы и создание интерактивной коммуникации в видеоформате. В связи с этим актуальным является вопрос мотивации развития цифровой компетентности у преподавателей и уровень развития автономного обучения у студентов. Оценивая уровень развития цифровой компетентности преподавателей на основе мониторинга самооценки, эксперты высказали единое мнение, что преподаватели педагогических факультетов в короткий срок значительно повысили уровень цифровых компетенций. Вместе с тем они отметили гетерогенность развития цифровых компетенций у преподавателей. Однако при мониторинге самооценки у многих преподавателей возникал вопрос по содержанию цифровых компетенций:

1) работа с информацией и грамотность в обработке информации;

2) интерактивный характер коммуникации и кооперации;

3) создание цифровых материалов;

4) безопасность и защита данных;

5) решение технических проблем.

Отсутствие широкого опыта по содержательным уровням цифровых компетенций или, например, использование программ, которые не лицензированы университетом, в целом осложнило определение самооценки цифровой компетентности у преподавателей. Особого интереса заслуживает дискуссия по теме разделения функций технического персонала и преподавателей в реализации цифрового образования. Следовательно, была выдвинута задача анализа понятия «цифровые компетенции», их соотнесенность с методическими компетенциями, чтобы определить горизонты дальнейшего развития цифровых компетенций преподавателей и студентов - будущих учителей с учетом университетской поддержки. Исследовательская группа сознательно отказалась от сравнения цифровых ресурсов университетов, так как сравнение не преследовало анализа предпринятых мер на институциональном уровне. В контексте обсуждения цифровых компетенций преподавателей важно было сформулировать новые тенденции развития педагогического образования будущего.

Таблица 2. Цифровые ресурсы для реализации педагогического образования

Table 2. Digital resources for the implementation of teacher education

\begin{tabular}{|l|l|}
\hline \multicolumn{1}{c|}{$\begin{array}{c}\text { Учебные } \\
\text { платформы }\end{array}$} & \multicolumn{1}{c|}{ Moodle, Opal, Opal Exam } \\
\hline Цифровые ресурсы & $\begin{array}{l}\text { Zoom (частные лицензии), Zoom (институциональные лицензии без ограничения } \\
\text { вренен - ТУ Дрезден), MS Teams, Google Meet, Skype, BigBlueButton, Jitsi, GoTo- } \\
\text { Meeting, E-Mail, Cloudstore, Dropbox, Facebook, Instagram, Whatsapp, Twitter }\end{array}$ \\
\hline $\begin{array}{l}\text { Расширение } \\
\text { учебных ресурсов }\end{array}$ & $\begin{array}{l}\text { бесплатный доступ к продуктам Microsoft Office 365; YouTube, электронный доступ } \\
\text { к фондам библиотеки, автоматическое продление литературы и количественная } \\
\text { неограниченность в выборе литературы на дом, медиотека и видеоресурсы }\end{array}$ \\
\hline
\end{tabular}


3. Для педагогического университетского образования в условиях пандемии Covid-19 были определяющими следующие вызовы (табл. 3).

4. Анализ международных кейсов преподавания и обучения на педагогических факультетах выдвинул новые смыслы терминов «образование» и «обучение» в условиях пандемии Covid-19 и их взаимозависимость от времени и места обучения. В качестве положительных следствий педагогического образования в условиях пандемии Covid-19 были отмечены: свободное планирование времени и места преподавания и обучения, положительная динамика посещения занятий (лекций и семинаров), виртуальная мобильность, возможность определения индивидуального темпа обучения, гибкость дидактических сценариев, использование обратной связи, повышение цифровой компетентности в использовании информационных технологий, апробация дидактических сценариев цифрового обучения (синхронное, а-синхронное); подготовка электронных лекций и пособий, интенсивность работы со студентами,

Таблица 3. Вызовы университетского педагогического образования

Table 3. Challenges for university teacher education

\begin{tabular}{|c|c|}
\hline Уровень & Вызовы \\
\hline Университета & $\begin{array}{l}\text { в том числе привлечение талантливых специалистов, создание благоприятной } \\
\text { среды для научного прогресса, обеспечение технической и квалификационной } \\
\text { поддержки для профессорско-преподавательского состава и студентов, } \\
\text { организация экзаменационных сессий и вступительных экзаменов, техническая } \\
\text { оснащенность обслуживающего персонала, создание программных } \\
\text { и управленческих баз данных и сервиса поддержки для дистанционного обучения, } \\
\text { обеспечение электронных ресурсов и сохранности банка данных, увеличение } \\
\text { объема письменной коммуникации }\end{array}$ \\
\hline $\begin{array}{c}\text { Педагогического } \\
\text { факультета }\end{array}$ & $\begin{array}{l}\text { в том числе подготовка виртуальных помещений для обучения и коммуникации, } \\
\text { формирование цифрового самоопределения, обеспечение эффективности } \\
\text { обучения и информационной доступности, адаптация учебных материалов, } \\
\text { обсуждение дидактических сценариев обучения с учетом предоставленных } \\
\text { электронных ресурсов (а-синхронное обучение, синхронное обучение, смешанное } \\
\text { обучение), организация курсов с целью развития цифровой компетентности для } \\
\text { преподавателей и студентов }\end{array}$ \\
\hline $\begin{array}{c}\text { Преподавания } \\
\text { (преподаватели) }\end{array}$ & $\begin{array}{l}\text { в том числе разработка цифрового сценария занятия, гетерогенный уровень } \\
\text { цифрового самоопределения преподавателей, неоднородный уровень технической } \\
\text { оснащенности преподавателей, разный уровень владения навыками работы } \\
\text { с электронными ресурсами и использование IT-технологий, адаптация авторских } \\
\text { курсов для электронных ресурсов; выбор, планирование и осуществление } \\
\text { цифрового обучения, планирование объема заданий и проверочных } \\
\text { и экзаменационных работ, организация межсетевогосотрудничества иеелизации } \\
\text { практики в школе, проведения экзаменов, ослабление отношений со студентами }\end{array}$ \\
\hline $\begin{array}{l}\text { Обучения } \\
\text { (студенты) }\end{array}$ & $\begin{array}{l}\text { в том числе разный уровень технической оснащенности (отсутствие камеры, } \\
\text { качественный интернет), ограниченный доступ к бесплатному интернету } \\
\text { в домашних условиях и неоднородное качество интернет-соединения, разный } \\
\text { уровень владения навыками работы с компьютером (при высокой компетентности } \\
\text { работы с телефоном отмечается дефицит работы с компьютером), прохождение } \\
\text { школьной практики в дистанционном формате, адаптация различных цифровых } \\
\text { платформ при посещении различных курсов, сложность понимания и выполнение } \\
\text { практических и лабораторных работ на расстоянии, увеличение объема заданий, } \\
\text { индивидуальное планирование учебного и свободного времени, формирование } \\
\text { автодидактических навыков обучения и своего стиля самообразования, } \\
\text { ослабление социальных связей на уровне студенчества }\end{array}$ \\
\hline
\end{tabular}


имеющими проблемы со здоровьем, увеличение возможностей индивидуальной работы со студентами и коллегами; законодательное введение мобильности работы и гибкости рабочего времени, расширение электронных ресурсов в университетской библиотеке.

В этом контексте были сформулированы следующие выводы:

(1) Термин «образование» в цифровом формате выводит на понимание его как структуры знаний, связанной с системой смыслов. В таком случае «образование в цифровом формате» обозначает структурное смыслообразующее самодвижение индивидуума, которое стимулируется системой и отношениями извне, но которое затем происходит как внутреннее качественное развитие, как автономный процесс внутреннего присвоения структуры знаний во взаимодействии с внешней культурой.

(2) Принятие термина «обучение» как открытие, познание и освоение нового и чужого знания подчеркивает значимость введения цифрового образования в условиях пандемии Covid-19, которое позволяет естественным путем создать горизонт относительной «незнакомости». В этом смысле образовательная работа, связанная с производством «не-знаний», т. е. с созданием интерфейсов к системно-структурным знаниям, которые еще не освоены, мотивирует не только педагогическое сообщество, но и всех граждан планеты к самообучению.

(3) Исходя из тезиса, что деятельность учителя направлена на передачу знаний, которые пользуются не только спросом, но и обеспечением доступа к возможностям обучения и сопровождения процессов обучения, которые на уровне индивидуума либо частично, либо еще не использованы, цифровое обучение обозначило новые темы развития педагогического исследования. Важным является в том числе исследование, насколько цифровые технологии, расширяя доступ к знаниям, включают в себя наблюдение и рефлексию и какова роль учителя в этом процессе.

(4) Эксперты единодушно признали факт, что успех образования в условиях пандемии лишь частично можно объяснить наличием или отсутствием технических проблем. Чаще всего эффективность образования зависит от отсутствия или признания деятельности учителей, качества общения и их трудностей, (не)ясных заданий, (отсутствия) культуры сотрудничества, наличия конкурентности и отсутствия или наличия доверия в процессе общения. Анализ педагогического образования в условиях пандемии Covid-19 вывел на признание важности нравственных ценностей, так как в педагогике обмен знаниями происходит в контакте людей, в данном случае с помощью техники. Но техника не заменит учителей в школе. Ректоры университетов и директора школ задаются одним вопросом, как и где они могут найти и удержать преподавателей и учителей, которые знают и умеют учить. Преподаватели, способные адаптировать новые технологии, в будущем будут работать только там, где их ценят, там, где им доверяют. Поэтому планирование трансформации педагогического образования лишь путем цифровизации не решает проблемы качества образования, в частности педагогического. В любой трансформации нужно увидеть смысл. Действительно впечатляющая составная цифровизации образования - это то, что она направлена на людей и общественные ценности. Цифровой формат образования возвращает нас к конкретным школьникам, студентам, коллегам, подчеркивая важность педагогизации учебной среды и общества. В условиях пандемии Covid-19 преподаватели работали в усиленном режиме, и инновационные технологии обучения сегодня плавно переходят в разряд традиционных. Если цифровой формат образования рассматривать с позиции повышения эффективности в процессе обучения, возникает новый смысл в использовании цифровых технологий после пандемии Covid-19, в осознании качества преподавательского сопровождения.

\section{Заключение}

В результате текущих социальнополитических и образовательных событий преподаватели педагогических дисциплин 
сталкиваются с различными вызовами, которые, как показал анализ, характерны для всех университетов - участников международной научной группы. Для развития глобальной педагогической среды были определены важные интернациональные задачи, которые обобщены в следующих целях развития педагогического образования в международном контексте: 1) развитие индивидуальности и кооперативного взаимодействия участников педагогического образования с с учётом возможностей цифровых технологий. Как показал анализ групповой дискуссии, участники педагогического образования уже сейчас неоднородны по своему составу. Следовательно, необходимо после пандемии не сужать, а создавать «гибкие» с точки зрения времени и места технологии, учебные сценарии с помощью цифровых учебных ресурсов, учитывая возможности как самостоятельного обучения, так и группового. Такая реализация индивидуальных и интерактивных процессов обучения для будущих педагогов поможет повысить значимость педагогических профессий и создания эффективного глобального педагогического образования. Отдельного рассмотрения заслуживает вопрос о количестве и качестве знаний и их сознательной переработке и структурировании преподавателями для очного и цифрового формата. (2) Для этого необходимо оказывать активную поддержку преподавателям в их развитии цифровой дидактической компетентности, чтобы они имели возможность самостоятельно планировать и реализовывать цифровые сценарии преподавания, совмещая теорию и практику в образовании будущих учителей, что в свою очередь способствует преподаванию, ориентированному на педагогическое исследование и, в частности, обогащение дидактических сценариев. (3) Педагогическое образование, организованное с цифровой поддержкой, поможет созданию модели «открытого» образовательного пространства, не отказываясь от очного формата, а лишь при изменении категории места и времени обучения, которое способствует развитию интернационализации педагоги- ческого образования и реализации учения на протяжении всей жизни. (4) Подведя промежуточные итоги, можно утверждать, что пандемия Covid-19 вызвала ситуацию стресса в образовании (Nikandrov, 2021; Zinchenko et al., 2021). Преподаватели и студенты вынуждены были выйти из зоны комфорта, что, однако, способствовало резкому качественному развитию образования в мире. (5) Компаративный анализ международный кейсов показал общность проблем, вызовов и педагогических смыслов пандемии. Различия на институциональном и социально-политическом уровнях оказывают влияние на качество и эффективность реализации цифрового образования. Осознание релевантности цифрового образования в условиях пандемии Covid-19 содействует формированию нового отношения к цифровым сценариям. Опыт преподавания в условиях пандемии Covid-19 можно и нужно использовать дальше в подготовке учителей, чтобы обучение в классной комнате становилось более гибким, современным, профессиональным и экологичным. Цифровое и гибридное обучение, форматы «смешанного обучения» или «перевернутого класса» необходимо использовать и дальше, так как это позволяет развивать методические и личностные компетенции, не отказываясь от формата очной школы как места педагогической встречи учащихся и учителей и как основного образовательного учреждения. Следовательно, введение и развитие цифрового образования должны стать не временным периодом в развитии дидактики обучения, a одной еe составляющей, направленной на интеграцию педагогических инноваций и обеспечение устойчивости образовательного процесса и эффективности педагогического образования в будущем, без отказа от формата личного контакта в педагогическом и школьном образовании. (6) Вопросы трансформации профессии «учитель» и эффективности преподавания и обучения в цифровом формате требуют новых исследований по теме цифрового самоопределения преподавателя-учителя и студентовучащихся. Какие возможности развития 
цифрового самоопределения для развития автономности обучения предлагают университетские программы подготовки учи- телей, предстоит проанализировать международному педагогическому сообществу в ближайшем будущем.

\section{Список литературы / References}

Arzhanova, I.V., Baryshnikova, M. Iu., Zavarykina, L.V., Nagornov, V.A., Perfir'eva, O.V. (2020). Vliianie pandemii Covid-19 na sector vysshego obrazovaniia i magistraturu: mezhdunarodnyi, natsionalnyi $i$ institutsionalnyi otvet, analiticheskii material [The impact of the Covid-19 pandemic on the higher education sector and graduate studies: The international, national and institutional response, analytical report]. Available at: https://ntf.ru/sites/default/files/Vliyanie\%20pandemii\%20COVID-19 \%20na\%20sektor\%20 vysshego\%20obrazovaniya\%20i\%20magistraturu.pdf (accessed 3 July 2021).

Becker, A., Stang, R. (2020). Lernwelt Hochschule: Dimensionen eines Bildungsbereichs im Umbruch. Verlag Walter de Gruyter GmbH, Berlin/Boston, $218 \mathrm{~S}$.

Duschinská, K., High, R. (2020). Reflexe nouzoví výuky: distanční přednášky předmětu základy didaktiky, In Pedagogická orientace, 30(2), 266-281.

Europäischer Rahmen für die Digitale Kompetenz von Lehrenden (DigComEdu) (2018). Available at: https://ec.europa.eu/jrc/sites/default/files/digcompedu leaflet de-2018-09-21pdf.pdf (accessed 4 July 2021).

Gafurov, I.R., Ibragimov, G.I., Kalimullin, A.M., Alishev, T.B. (2020). Transformatsiia obucheniia v vysshei shkole vo vremia pandemii: bolevye tochki [Transformation of higher education during the pandemic: Pain points], In Vysshee obrazovanie v Rossii [Higher Education in Russia], 29(10), 101-112.

Galazhinskii, E. (2020). Uroki stress-testa: vuzy v usloviiakh pandemii i posle nee [Lessons from the stress test: Universities during and after the pandemic]. Available at: http://www.tsu.ru/news/uroki-stresstesta-vuzy-v-usloviyakh-pandemii-i-po/?sphrase id=294888 (accessed 3 July 2021).

Heimann, P. (1976). Didaktische Grundbegriffe. Vortrag vom 7.12.1961. In P. Heimann (Hrsg.), Didaktik als Unterrichtswissenschaft. Herausgegeben und eingeleitet von Kersten Reich und Helga Thomas (S. 103-121). Stuttgart: Klett.

Ivanova, M.A. (2021). Дигитално образование по време на пандемия - възможности и ограничения [Digital education during a pandemic - opportunities and limitations]. Available at: http://eprints.nbu.bg/4360/1/Doclad_MAI.pdf (accessed 22 July 2021).

Leont'ev, D.A. (1999). Psikhologiia smylsa. Priroda, stroenie i dinamika smyslovoi real'nosti [Psychology of meaning: nature, structure and dynamics of semantic reality]. Available at: https://lib.uni-dubna. $\mathrm{ru} / \mathrm{search} /$ files/psy leo_psy smisla/1.pdf (accessed 3 July 2021).

Menter, I. (Ed.). (2021). Teacher Education in Russia. Past, Present and Future. London, Routledge, $236 \mathrm{p}$.

Mizova, B., Peytcheva-Forsyth, R., Gospodinov, B. (2021). Challenges to the development of teacher' professional digital competences - Bulgarian perspective. AIP Conference Proceedings 2333, 050012 (2021). https://doi.org/10.1063/5.0041818

Nikandrov, N.D. (2021). Tsivrovizatsiia: potentsial, dostizheniia, riski [Digitalization, its potentiality, achievements and risks], In Mir Psikhologii [World of Psychology], 1-2(105), 75-88.

Pasternak, P., Schneider, S., Trautwein, P., Zierold, A. (2018). Die verwaltete Hochschulwelt. Reformen, Organisation, Digitalisierung und das wissenschaftliche Personal. Berlin, Wissenschaftsverlag, 362 S.

Vančura, M., Rokos, L. (2020). Distanční výuka při opatřeních spojených s koronavirovou pandemií pohled očima učitelů, žáků a jejich rodičů, In Pedagogická orientace, 30(2), 122-155.

Zinchenko, Yu.P., Shaigerova, L.A., Almazova, O.V., Shilko, R.S., Vakhantseva, O.V., Dolgikh, A.G., Veraksa, A.N., Kalimullin, A.M. (2021). The Spread of COVID-19 in Russia: Immediate Impact on Mental Health of University Students, In Psychological Studies, 1-12. 